\title{
CORRESPONDENCE
}

\section{GEOSCIENCE EDUCATION}

Dr. A.K. Singhvi wrote an editorial essay in the Dec. 2020 issue of the the Geological Society of India's flagship journal, with an apology for doing so, as only Late Dr. BP Radhakrishna (BPR) had the privilege of using the edit page to editorialise his views on all facets of the state and status of geosciences in the nation vis-à-vis globally. In being an associate of the Society right from the late 60's and as a Fellow later on, I enjoyed reading the points raised in the editorials of BPR.

Now, Dr. Singhvi's essay is mostly generally about the current state of geoscience education and research in the nation and he has concluded his essay by adding a fairly long list of suggestions including, study of the solid Earth, earth surface processes, disasters, hydrogeology and so on.

In the following, I add some specific points in revamping geoscience education at the college (B.Sc. degree teaching and learning) and university (M.Sc., and Ph.D.) levels. At the outset, I, also wish to underscore the lack of synergy between the premier survey organisation in the country, i.e., the Geological Survey of India, now logging 177 years of service to the nation and the academia.

The Geological Society, all along has primarily focused on the publication of its flagship journal, memoirs and special papers or occasionally books. Certainly it is a commendable service rendered to the community of students, academics and researchers.

However, the Society has elected to stay away from taking the vision or mission of the discipline or profession of geosciences to the people in authority or possessing powers to influence the national policy on the role of geosciences in nation building, technology development, or needs to identify or pin point thrust areas in exploration, research or framework of geologic education.

Secondly and sadly, there is no single source book or webpage, where from one could get the number and contact addresses of the colleges offering undergraduate geological education in the country or for that matter number of colleges and universities along with the postal or e-mail addresses, where MSc and PhD degree can be pursued. I thought, filling this gap should have been taken up by the Society at least a decade ago.

Thirdly, I believed and continue to believe that the Society should have chosen to be at the intersection of geological education, research, and professional organisations in the country and national government agencies with linkages to geoscience education, profession and research. Such a positioning would have perhaps totally redrawn the map of education, protocol of research priorities and above all societal services of the science of geosciences.

The Geological Survey of India, founded in the days of the British Raj, continues to be one of the primary employers of professional geologists in the country. Unfortunately, the GSI has a very poor presence in the activities of the Geological Society of India for reasons that are obvious or opaque. I wish that this distancing should change for good for the future of the science, of the profession and security of the citizen of India living in the geologically challenged environments.

Furthermore, I suggest that the Geological Survey of India, creates a virtual museum of rocks, minerals, fossils etc that can be shared by geoscience students as well as curious others across the country and perhaps SE Asian and African countries.

In the same vein, hordes of scientists of the Geological Survey of India, walking over rock formations of the country during a fair half of FY, be mandated to collect video clips, in order to put together suitable web content of virtual field trips to typical field settings, contacts and unconformities, faults or fault traces, outcrops of typical rock formations, type areas etc. Such a collection, can be immensely rewarding to the new generation of students who plan to visit field areas as part of their field study programs.

Currently, a sea change is underway in the arena of college and university education enshrined in the new National Education Policy, 2020. I fervently hope and desire that the Geological Society with the human resources it can command among the Fellows of the Society, develops a model four-year-college curriculum for geoscience majors as well as a PG level course content for adoption in the universities and colleges in India.

Finally, I wish to thank the Society for providing an arena for Dr. A.K. Singhvi to share his well thought out views on the what's and why's of the state of our education, research and profession.

10, BG Lily,

K.P. THRIVIKRAMJI

Thirumala $P O$,

Trivandrum - 695006

E:thrivikramji@gmail.com 